\title{
Seasonal steroid variations in relation to maturity stages in the female Pacific red snapper Lutjanus peru in the Gulf of California, Mexico
}

\author{
Silvie Dumas ${ }^{1, *}$, Silvia Ramirez Luna ${ }^{1}$, Pablo Pintos Terán ${ }^{3}$, Evaristo Mañanos ${ }^{2}$ and Lluis Tort ${ }^{4}$ \\ ${ }^{1}$ Instituto Politécnico Nacional, Centro Interdisciplinario de Ciencias marinas, Unidad Piloto de Maricultivos, PO Box 592, La Paz, \\ B.C.S. 23000, Mexico \\ ${ }^{2}$ Instituto de Acuicultura de Torre la Sal (IATS-CSIC), 12595-Ribera de Cabanes, Castellón, Spain \\ ${ }^{3}$ Universidad del Mar. Ciudad Universitaria. Puerto Ángel, Oaxaca 70902, Mexico \\ ${ }^{4}$ Department Cell Biology, Physiology and Immunology, Universitat Autónoma de Barcelona, 08193 Bellaterra, Spain
}

Received 28 February 2018 / Accepted 19 September 2018

Handling Editor: Pierre Boudry

\begin{abstract}
Reproductive steroid concentration and gonadal development as well as plasma cortisol were investigated during the reproductive period (April to October) of the Pacific red snapper Lutjanus peru, a commercial and important local fishery species in the surrounding areas of Bahía La Paz, Gulf of California, Mexico. Gonads in April were immature and characterized by the presence of oocytes at the chromatin nucleolar and perinucleolar stages. In the next month, more than 50\% of the fish showed gonads in vitellogenesis, characterized by the presence of cortical alveoli and early vitellogenic (V1) oocytes. Late vitellogenic and mature gonads were present in July, August and September. Postovulatory follicles were observed only in gonads collected in August, indicating spawning activity of these individuals. The gonadosomatic index (GSI) increased significantly $(p<0.05)$ from April and May to July, when it reached its maximum value. A significant increase $(p<0.05)$ in plasma testosterone $(\mathrm{T})$ was also observed in July compared to previous months, and plasma estradiol (E2) concentration was significantly higher $(p<0.05)$ in September than in April. Cortisol concentration was significantly higher $(p<0.05)$ in September than in May. Significant differences $(p<0.05)$ between gonadal stages were observed for GSI and E2 but not for T. We conclude that the Pacific red snapper, in the surrounding areas of Bahía de la Paz, showed an asynchronous ovarian growth starting in May when water temperature increased and that was characterized by several spawning events.
\end{abstract}

Keywords: Estradiol / testosterone / cortisol / oocyte / gonadal maturation

\section{Introduction}

The Pacific red snapper Lutjanus peru (Nichols and Murphy) is an important commercial species of Mexico's artisanal fisheries. It inhabits offshore waters, at least $90 \mathrm{~m}$ deep (Allen and Robertson, 1994) from the North coast of Peru to Bahía Magdalena, Baja California Sur, Mexico, and the southern Gulf of California, Mexico. The Pacific red snapper's high market value as a food fish is generating a strong interest in developing its culture. As a result, it is the object of investigation of several groups in Mexico, some of them focusing on the understanding of the reproductive cycle of this important species, not only for the future development of adequate aquaculture but also for fisheries management

\footnotetext{
* Corresponding author: silviedumas@hotmail.com
}

strategies and the development of conservation and management strategies of its population. Studies on fish reproduction are necessary to assist the aquaculture industry in meeting optimized protocols of egg production and enhanced progeny viability (Lubzens et al., 2010).

The reproductive activity of the Pacific red snapper has been described in different areas of the Pacific Coast of Mexico (Santamaria Miranda, 1998; Reyna-Trujillo, 1993). The reproductive season extends from May to July, with another small peak in September in Bahía de La Paz (Reyna-Trujillo, 1993), and extends from February to September in the coastal state of Guerrero (Santamaria Miranda, 1998). Although sexual maturation has been induced in captivity, using an annual photothermal regime success has been limited, and few females and males produced mature gametes (Dumas et al., 2004). 
There are no studies on the endocrine regulation of gametogenesis in this species. Basic understanding of the gonadal and hormonal changes during the reproductive cycle is necessary to elucidate the physiological and environmental mechanisms that govern reproduction in this fish species. To develop a baseline knowledge on the reproductive biology of wild populations, studies on the gonad maturity process usually focus on the seasonal variations in steroid patterns and gonadal growth (gonadosomatic index), and description of micro- (histology) and macroscopic characteristics of the gonads (Hunter et al., 1992). A positive correlation between plasma concentrations of estradiol (E2) and testosterone (T) and the development of oocytes is the general rule and is has been described in many teleost fishes (Rinchard et al., 1997; Kokokiris et al., 2001; King and Pankhurst, 2003).

The aim of this study was to provide new information on the reproductive cycle of the Pacific red snapper by quantifying seasonal changes in plasma levels of sexual steroids (E2 and T) as well as by providing the histological description of the gonads related to environmental variables. The steroidogenic activity of Pacific red snapper was analyzed in wild fish, so this pattern could be replicated in the future in fish under rearing conditions. We also assessed the levels of cortisol for several reasons, one is that this hormone is closely related to sexual steroids as they share the same metabolic pathway from cholesterol leading to testosterone or cortisol synthesis; therefore, the production of reproductive hormones may affect the ability to synthesize higher or lower amounts of cortisol. In fact, it has been shown in several species that acute stress induces a significant increase of cortisol concomitantly with a decrease of testosterone, and other studies also showed decreases in 11-ketotestosterone, estradiol or vitellogenin (for a review, see Pankhurst, 2016). On the other side of the argument, we also wanted to assess whether fish would be significantly affected by capture stress and therefore show high levels of cortisol, which could involve that the levels of other steroid reproductive hormones could be affected.

\section{Materials and methods}

Fish were captured by hook and line in the surrounding areas of Bahía de La Paz, B.C.S., Mexico, at approximately monthly intervals, from April to September 2002. Immediately after capture, blood was quickly collected by heart or caudal puncture with heparinized syringes and placed in ice-cold heparinized tubes (Mañanós et al., 1994). Blood was centrifuged at $1500 \mathrm{~g}$ for $10 \mathrm{~min}$ at $4{ }^{\circ} \mathrm{C}$ and the resulting plasma stored at $-80^{\circ} \mathrm{C}$ for further analysis of steroids. Each fish was measured for total length $( \pm 1 \mathrm{~mm})$ and weight $( \pm 1 \mathrm{~g})$. Gonads were excised and kept on ice for further processing. Superficial water temperature was measured and photoperiod was calculated for the region at $24^{\circ} 13^{\prime} \mathrm{N}$ and $110^{\circ} 18^{\prime} 30^{\prime \prime} \mathrm{W}$, in La Paz, B.C.S., Mexico.

\subsection{Analysis of gonads and histology}

At the laboratory, gonads were weighed $( \pm 0.01 \mathrm{~g})$ and the Gonadosomatic index (GSI) calculated by the formula $\mathrm{GSI}=($ gonad weight/eviscerated total fish weight $) \times 100 . \mathrm{A}$ portion of ovarian tissue from the central part of the gonad was excised and fixed in Davidson solution (Leslie, 1983) for $24-48 \mathrm{~h}$ and then, transferred to ethanol $70 \%$ for further histological processing. Ovarian pieces were dehydrated in a series of increasing concentrations of ethanol and embedded in paraffin. Sections were cut at $5 \mu \mathrm{m}$ and stained with hematoxylin-eosin.

Histological sections were analyzed under the microscope to identify the different stages of oocyte development, based on the criteria established in previous histological studies of the fish ovary (Selman and Wallace, 1989; Grau et al., 1996; Tyler and Sumpter, 1996; Núñez and Duponchelle, 2009), including the studies on Pacific red snapper (Reyna-Trujillo, 1993; Lucano-Ramírez et al., 2001). The diameter of oocytes at each developmental stage (minimum of 50 measurements for each stage) was measured, over photographs taken from the histological slices and image analysis. Based on this information, eleven stages of oocyte development were identified: (1) oogonia (Oog), small cells with a voluminous nucleus containing a single prominent nucleolus and forming clusters or nests, (2) chromatin-nucleolar (CN; 9-28 $\mu \mathrm{m}$ oocyte diameter), primary oocytes with a strongly basophilic cytoplasm and a high nucleus/cytoplasm (N/C) ratio, with one or several small nucleoli, (3) perinucleolar (PN; 18-120 $\mu \mathrm{m}$ oocyte diameter), evident increase in size of the cytoplasm that is uniformly stained at initial phases (average oocyte diameter $39 \mu \mathrm{m}$ ) and become unevenly stained at late phases (average oocyte diameter $74 \mu \mathrm{m}$ ) concomitantly with the appearance of multiple nucleoli within the nucleus, (4) cortical alveolus (CA; 91-199 $\mu \mathrm{m}$ oocyte diameter), characterized by the appearance of a layer of round globules (cortical alveoli) in the cortical zone of the cytoplasm and a thin but evident zona radiata surrounding the oocyte, (5) initial vitellogenesis (V1; 156-292 $\mu \mathrm{m}$ oocyte diameter), characterized by the appearance of lipid globules and yolk granules, which in this initial phase are small and grouped in defined layers within the cytoplasm, (6) mid vitellogenesis (V2; 182-356 $\mu \mathrm{m}$ oocyte diameter), lipid globules and yolk granules increase in number and size and accumulate progressively through the entire cytoplasm, (7) late vitellogenesis (V3; 207-407 $\mu \mathrm{m}$ oocyte diameter), the oocyte cytoplasm is fully occupied by globules and granules and the zona radiata is at its maximum development, (8) initial maturation (M; 302-445 $\mu \mathrm{m}$ oocyte diameter), clearly distinguishable because of the migration of the germinal vesicle to the animal pole and the progressive coalescence of the lipid globules and yolk granules, (9) late maturation (hydrated) (H; 323-692 $\mu \mathrm{m}$ oocyte diameter), characterized by the absence of the nucleus, the complete coalescence of globules and granules and the high increase in oocyte size due to water uptake (hydration), (10) postovulatory follicles (POF), flat folded structures corresponding to the empty follicular envelopes after the ovulation of the oocyte, (11) atresia (ATR), visible as a compact highly vascularized structure, showing the fragmentation of the vitelline envelope, hypertrophy of the follicle cells and the progressive resorption of the cytoplasmic content.

The stages of ovarian development were determined after macroscopic examination of the gonads and microscopic analysis to identify the presence of the most advanced oocyte stage within the ovary, following the criteria established previously for L. peru (Reyna-Trujillo, 1993) and classified as 
follows: (1) immature/resting, undeveloped small ovaries containing nests of oogonia and oocytes at stages $\mathrm{CN}$ and $\mathrm{PN}$, (2) vitellogenic, still small ovaries but clearly developing, with an increment in blood irrigation and adipose tissue surrounding the ovary and the presence of CA and vitellogenic (V1-V2) oocytes, (3) late vitellogenic, fully developed and voluminous ovaries containing oocytes at different vitellogenic stages but predominantly post-vitellogenic (V3) oocytes, (4) mature, corresponding to highest GSI and characterized by the presence in the ovary of batches of oocytes entering the maturation process (migrating or peripheral position of the germinal vesicle, coalescence of the cytoplasmic globules and granules and hydration), together with $\mathrm{V} 3$ vitellogenic oocytes (as well as other previous vitellogenic stages) and in some cases, the presence of post-ovulatory follicles, indicating spawning activity.

\subsection{Analysis of steroids in plasma}

Plasma samples were lyophilized and transported to different Spanish laboratories for the analysis of estradiol (E2) and testosterone (T) (IATS-CSIC, Castellón) and cortisol (UAB, Barcelona), by enzyme-linked immunosorbent assay (ELISA) and radioimmunoassay (RIA), respectively.

For E2 and T analyses, lyophilized plasmas were first reconstituted in assay buffer $(0.1 \mathrm{M}$ potassium phosphate buffer, $\mathrm{pH}$ 7.4) and extracted with methanol (Guzmán et al., 2008). Extracted pellets were resuspended in assay buffer and stored at $-20^{\circ} \mathrm{C}$ until ELISA analysis. ELISAs for E2 and T used the protocols previously developed by Rodriguez et al. (2000) and Guzmán et al. (2008) and validated for the Pacific red snapper, by checking the parallelism between the E2 and $\mathrm{T}$ standard curves and displacement curves obtained by serially diluted plasma. Extraction efficiency has been previously tested for both E2 and T ELISAs (Rodriguez et al., 2000; Guzmán et al., 2008), on recovery tests of spiked samples; in all cases, recoveries were around 90-105\%, which was considered not significant and thus, no correction factor is applied on the E2 and T analysis. Plasma samples were always analyzed at a minimum 10 -fold dilution, to avoid non-specific matrix effects in the assay. Briefly, the ELISA protocol was performed as follows: Mouse anti-rabbit IgG monoclonal antibody (Sigma)-coated 96-well microplates were first blocked with $2 \%$ BSA assay buffer and then, incubated (overnight at $4{ }^{\circ} \mathrm{C}$ ) with a mixture containing $50 \mu \mathrm{l}$ of standard (E2 or T; Sigma) or sample (replaced with assay buffer in wells for maximum binding and nonspecific binding $(100 \mu l)), 50 \mu \mathrm{l}$ of specific antibody (AbE2 or AbT) solution (all wells except those for nonspecific binding) and $50 \mu \mathrm{l}$ of the specific acetylcholinesterase tracer (AChE-E2 or AChET; Cayman Chemical, MY, USA) solution. After washing, color development was achieved by incubation with Ellman's reagent ( $4 \mathrm{~h}$ at room temperature; complete darkness) and absorbances read at $405 \mathrm{~nm}$ using a microplate reader. The specific antibodies for E2 (AbE2) and $T$ (AbT) were produced previously in our laboratory (Prat et al., 1990) and used in the ELISAs at a final dilution of $1: 800,000$ and 1:1,600,000, respectively. The cross-reactivity of the AbT with other steroids was $31 \%$ with 11 -ketotestosterone, $41 \%$ with $5 \alpha$-dihydrotestosterone, $14 \%$ with androstendione, $2 \%$ with $5 \alpha$ androstan- $3 \alpha, 17 \beta$-diol, $6 \%$ with $5 \alpha$-androstan- $3 \alpha, 17 \beta$-diol,
$0.2 \%$ with $11 \beta$-hydroxyandrostendione and $<0.1 \%$ with other tested steroids. The cross-reactivity of the AbE2 was $3 \%$ with estrone, $3 \%$ with 6 -ketoestradiol- $17 \beta, 3 \%$ with 16 -ketoestradiol-17 $\beta, 2 \%$ with 16 -epiestriol, $0.3 \%$ with estriol and $<0.1 \%$ with other tested steroids. The sensitivities of the ELISAs, calculated as $\mathrm{Bo} \pm 2 \mathrm{SD}$ (maximum binding minus twice the standard deviation), were $5.2 \mathrm{pg} / \mathrm{ml}$ and $8.8 \mathrm{pg} / \mathrm{ml}$ for the E2 and T ELISA, respectively. The intra- and interassay coefficients of variation ( $\mathrm{CV} \%$ ), checked at $50 \%$ binding by analyzing the same sample in the same (intra-assay variability, $n=4$ ) or in different (interassay variability, $n=8$ ) assays, were 6 and $7 \%$ for E2 and 6 and $11 \%$ for T ELISA.

Cortisol was determined following the method used by Rotllant et al. (2006) in Sparus aurata, at the Department of Cell Biology, Physiology and Immunology, Universidad Autónoma de Barcelona. Cortisol levels were measured by radioimmunoassay, and the radioactivity was quantified using a liquid scintillation counter (Scintillation Counter Wallac 1409, PerkinElmer). Anti-cortisol antibody was used for the assay at a final dilution of 1:4500. Antibody crossreactivity with cortisol is $100 \%$ and the lower detection limit of the assay was $0.16 \mathrm{ng} / \mathrm{ml}$. Cross-reactivity with other steroid hormones varied from $1.6 \%$ for corticosterone and was inferior to $0.7 \%$ for $17 \alpha$-hydroxyprogesterone, cortisone, desoxycorticosterone, $17 \alpha$-hydroxypregnenolone, dexamethasone, progesterone, aldosterone, cholesterol, estradiol and testosterone. The lower detection limit of the cortisol assay is $0.16 \mathrm{ng} / \mathrm{ml}$. Samples were diluted in the ratio $1: 11$.

\subsection{Statistics}

Results were analyzed using Statistica v.8. As data were not normally distributed, Kruskal Wallis tests using months or gonadal stage as factor was performed in separated tests. When significance was detected, a posteriori test analysis was performed and Z-value was calculated.

\section{Results}

Average total length and weight of individuals was over $485 \mathrm{~mm}$ and $1650 \mathrm{~g}$ except for the month of April when the captured fish showed average total length between 365 and $455 \mathrm{~mm}$ and weight of $711 \mathrm{~g}$ (Tab. 1). Thirty-six fish were captured over these 6 months.

\subsection{Gonad development}

The most advanced oocyte development stage observed in each individual for each month is shown in Figure 1. In April, the ovaries were still in the resting phase and $75 \%$ of the gonads showed perinucleolar oocytes (PN) as the most advanced oocyte development stage, while $25 \%$ showed oocytes at the cortical alveoli (CA) stage (Figs. 1 and 2a). In the next month (May), gonads showing PN decreased to $29 \%$ and gonads showing $\mathrm{CA}$ and $\mathrm{V} 1$ as the most advanced stage were 29 and 43\%, respectively, (Figs. 1 and 2b). In July, August and September, more than $40 \%$ of the gonads showed V3 and mature oocytes. In July, atresia of late vitellogenic 
Table 1. Total length (TL), weight $(W)$, number of organisms $(n)$ and temperature $(T)$ of Pacific red snapper females sampled in Bahía de La Paz, B.C.S., Mexico during the reproductive cycle from April to September.

\begin{tabular}{lllll}
\hline Months & TL $(\mathrm{mm})$ & $W(\mathrm{~g})$ & $n$ & $T\left({ }^{\circ} \mathrm{C}\right)$ \\
\hline April & $391.4(25.6)$ & $711.4(164.3)$ & 7 & 22.5 \\
May & $555.7(82.8)$ & $1957.8(1095.0)$ & 7 & 24 \\
July & $621.0(55.2)$ & $2588.5(477.1)$ & 7 & 8 \\
August & $634.4(37.3)$ & $2706.9(440.0)$ & 7 & 28 \\
September & $537.9(41.3)$ & $1651.4(402.8)$ & 31 \\
\hline
\end{tabular}

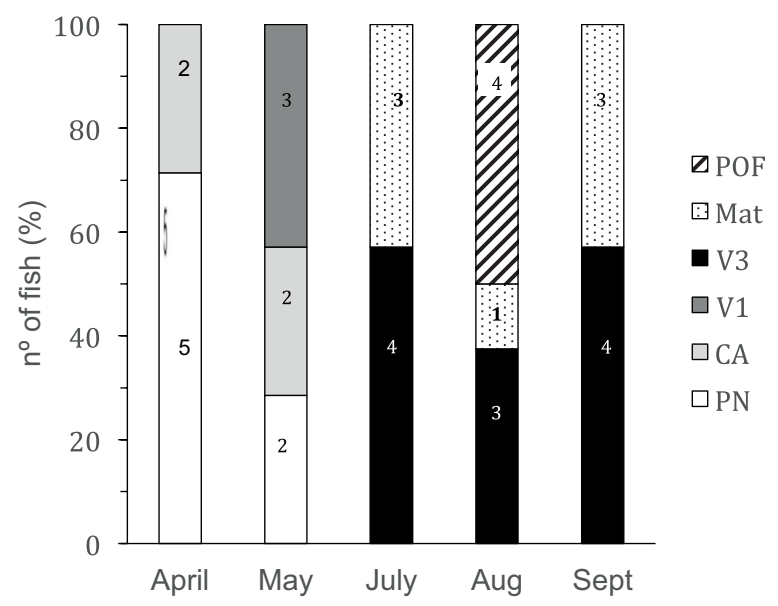

Fig. 1. Number of fish (\%) characterized by the most advanced oocyte stage in each month. PN: perinucleolar oocyte; CA: cortical alveoli oocyte; V1: initial vitellogenic oocyte; V3: late vitellogenic oocyte; POF: post-ovulatory follicles; M: mature.

oocytes were present in almost all sampled females. In August, $53 \%$ of the gonads had postovulatory follicles.

The seasonal evolution of the GSI showed a significant increase in July, August and September compared to April. No significant differences were detected between July, August and September (Fig. 3a).

\subsection{Testosterone, estradiol and cortisol plasma levels}

Significant differences were observed between months for T $(p=0.0042)$ and E2 $(p=0.0046)$ (Fig. 4). Plasma levels of $\mathrm{T}$ were lowest in April and increased progressively to peak values in July, which were significantly different from basal April concentrations, decreasing slightly thereafter but not significantly different from July. Significant differences in plasma E2 were observed only between April and September. Plasma cortisol did not show seasonal variations but significant differences were observed between concentration in May and peak values in September $(p=0.0394)$ (Fig. 5).

When GSI and hormones were analyzed in the different gonadal stages, significant differences were observed for GSI $(p=0.0000)$ and E2 $(p=0.0046)$ but not for T $(p=0.656)$ (Figs. $3 b$ and 6). A significantly higher GSI and E2 concentrations were observed in the late vitellogenic and mature gonads compared to IMM.

\section{Discussion}

The simultaneous presence of all oocyte developmental stages in the spawning specimens indicates that the Pacific red snapper, like another Lutjanidae from the Gulf of Mexico, Lutjanus campechanus (Jackson et al., 2006), is multiple spawner.

In warm water fishes, vitellogenesis begins shortly before the spawning season (Lowerre-Barbieri et al., 2011). In fact, in the Pacific red snapper, T and E2 plasma levels were low in April before the beginning of exogenous vitellogenesis. In this month, only perinucleolar and cortical alveoli oocytes were present in the ovary and the GSI was low. When steroid plasma levels were studied in correlation with the gonad developmental stage, E2 showed low values in immature females while T values, without being significantly different from those observed in immature females, showed a wider variation in the vitellogenic stage. A first increase of $\mathrm{T}$ at the stage of endogenous vitellogenesis has been reported in other teleosts and could be related to either a possible role in the formation of lipid droplets (Kobayashi et al., 1987) or to the role of $\mathrm{T}$ as precursor for the synthesis of E2, as described in most teleost fishes (Kagawa et al., 1983a).

In April, fish total lengths were smaller than in the other months. However, they were over the size reported for first sexual maturation in this species in the same area of the Gulf of California (Reyna-Trujillo, 1993) and in a southern population in Guerrero, Mex. (Santamaria Miranda, 1998). These small individuals could have been recruited into the reproductive population for this year. In the following months, fish size increased markedly. While some lutjanids such as lane snapper Lutjanus synagris (L) spawn close to their home reefs, others, such as dog snapper Lutjanus jocu (Bloch \& Schneider) and cubera snapper Lutjanus cyanopterus (Cuvier), migrate over large distances to spawn in transient aggregations (Domeier and Colin, 1997). Aggregations during the reproductive period in this area is a possible alternative, since Reyna-Trujillo (1993) - who have sampled all year round - found the biggest individuals during the active reproductive period of the year, similar to what we found in the present study.

Temperature increased in the month of July. Common exogenous cues that set off gonadal development in fishes are photoperiod (Bromage et al., 2001) and water temperature (Lam, 1983). In warm water species with extended spawning seasons, gonadal development tends to be stimulated by an interaction between photoperiod and temperature (Pankhurst and Porter, 2003). In July, the increase in GSI and plasma levels of $\mathrm{T}$ and E2 was correlated with the presence of late 


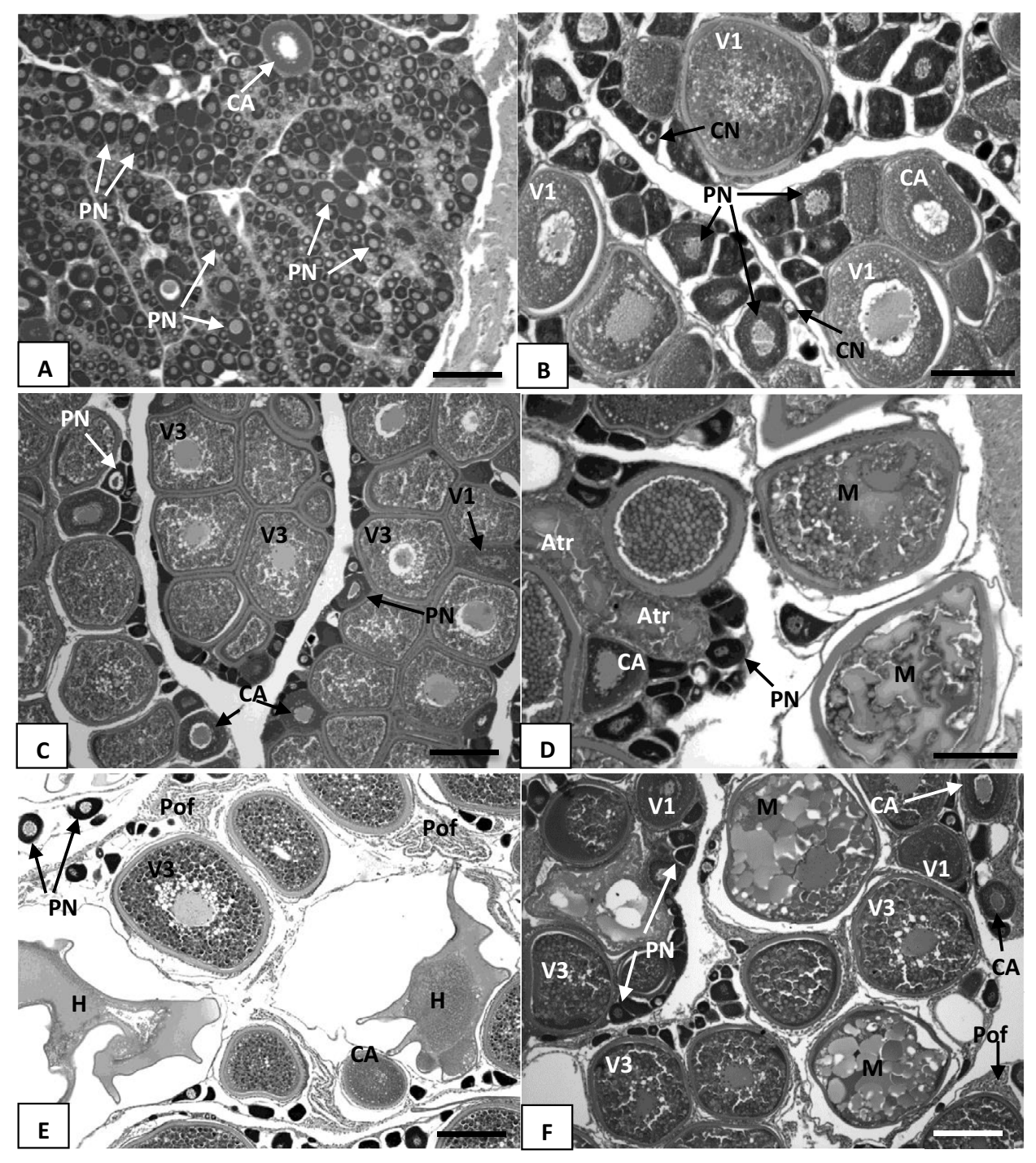

Fig. 2. Transverse sections of ovary in each month during the reproductive cycle (a) April (bar: $150 \mu \mathrm{m})$, (b) May (bar: $100 \mu \mathrm{m})$, (c) July (bar: $150 \mu \mathrm{m}$ ), (d) July (bar: $100 \mu \mathrm{m}$ ), (e) August (bar: $150 \mu \mathrm{m}$ ), (f) September (bar: $150 \mu \mathrm{m}$ ). CN: chromatine nucleolar oocyte; PN: perinucleolar oocyte; CA: cortical alveoli oocyte; V1: initial vitellogenic oocyte; V3: late vitellogenic oocyte; M: mature oocyte; POF: post-ovulatory follicle; Atr: atretic oocyte.

vitellogenic and mature oocytes in the gonads. Similar patterns have been reported in other multiple spawning fish such as Carassius auratus (Kagawa et al., 1983b), Pagrus major (Matsuyama et al., 1988), Dicentrarchus labrax (Prat et al., 1990), Gobio gobio (Rinchard et al., 1993) and Pagrus auratus (Carragher and Pankhusrt, 1993). This is consistent with the role of E2 as inducer of vitellogenin synthesis in teleosts (Specker and Sullivan, 1994).

The maturation of the females was clearly evident in July by the abundance of late vitellogenic and mature oocytes in the ovary, but spawning events would only be happening in August, as inferred by the presence of post-ovulatory follicles in this month. For the same species in the same area, ReynaTrujillo (1993) reported gonads with late vitellogenic oocytes in the month of July, but did not mention any sign of final maturation or spawning. For the same species but in a southern area of the Mexican coast, Santamaria Miranda (1998) reported two spawning events. We did not sample between
November and March, since Reyna-Trujillo (1993) did not observe reproductive activity in these months.

Follicular atresia was observed in the month of July when the females showed late vitellogenic or mature oocytes in the gonads. Ovarian follicular atresia has been described in several teleost species (Guraya, 1986). A high incidence of atretic oocytes has been interpreted as a sign of cessation of spawning activity (Hunter et al., 1986) or failure in attainment final oocyte maturation (Mylonas et al., 1997). It has also been proposed as a mechanism of fecundity regulation in wild herrings (Kurita et al., 2003). Atresia has been observed under natural and culture conditions and has been associated with stress, starvation, photoperiod regimes, sub-optimal water quality and unfavorable temperature. However, even with El Niño's warm phase occurring the year that fish were sampled, temperatures in July did not reach the maximum observed in September. In blue fin tuna Thynnus thynnus, Corriero et al. (2003) observed a high level of vitellogenic atresia in females 

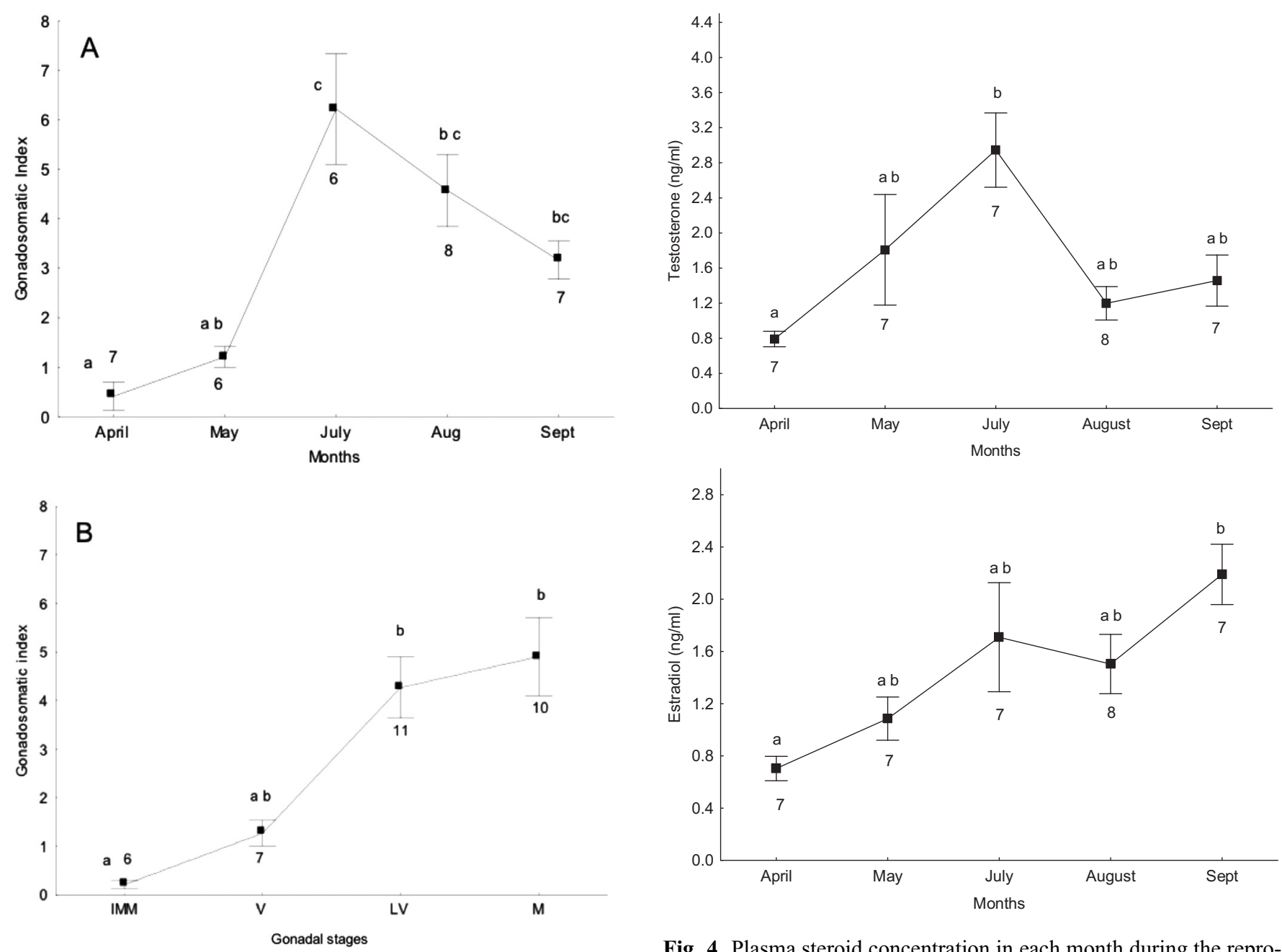

Fig. 3. Gonadosomatic index (GSI), (a) for each month, (b) for each gonadal stage (number of individuals in each month or gonadal stage). IMM: immature; V: Initial vitelogenesis; LV: late vitellogenisis M: mature. Different letters indicate significant differences $(p<0.05)$.

without any sign of spawning. These females were sampled in an area not identified as a spawning area. The authors suggested that mature females inhabiting nonspawning areas during the spawning season reabsorb their yolk reserve and do not spawn.

Late vitellogenic and mature females were characterized by high concentrations of E2, as reported in other multiple spawners such as white bream Blicca bjoerkna (Rinchard et al., 1997) and red porgy, Pagrus pagrus (Kokokiris et al., 2000). Significantly higher plasma levels of E2 were also observed in September, compared to basal April levels, when most of the females still showed gonads in late vitellogenic stage. High E2 levels have been observed during the spawning period of other multiple spawners with a continuous process of oocyte recruitment and with active vitellogenesis over the entire reproductive season (Kagawa et al., 1983a, Prat et al., 1990; Pavlidis et al., 2000). No significant difference between levels of $\mathrm{T}$ was observed between the different gonadal stages.

Steroid concentrations can vary significantly between fish species. Low steroid levels have been observed in captive

green flounder Rhombosolea tapirina (Sun and Pankhurst, 2004), captive channel catfish Ictalurus punctatus (Barrero et al., 2007) and captive Senegal sole Solea senegalensis (Oliveira et al., 2009), whereas they were slightly higher in European sea bass (Asturiano et al., 2000). E2 and T levels measured in this study are similar to those observed by Kokokiris et al. (2000) in wild P. pagrus. These authors argued that these low concentrations are probably due to the stress of capture, which has been shown to decrease plasma levels of sex steroids (Pickering et al., 1987), but they do not discuss cortisol concentration, although it may be expected to significantly increase. Studies differ about the inhibitory and stimulatory effects of corticosteroids and stress on reproduction (Milla et al., 2009). In fact, while Clearwater and Pankhurst (1997) measured high levels of E2 and cortisol in wild red gurnard just after capture, in our study, with only a maximum of $10 \mathrm{~min}$ elapsing time between fish capture and sampling, cortisol levels were below the ones reported by Grutter and Pankhurst (2000) for unstressed fish from different species. This suggests that sampling was quick enough to 


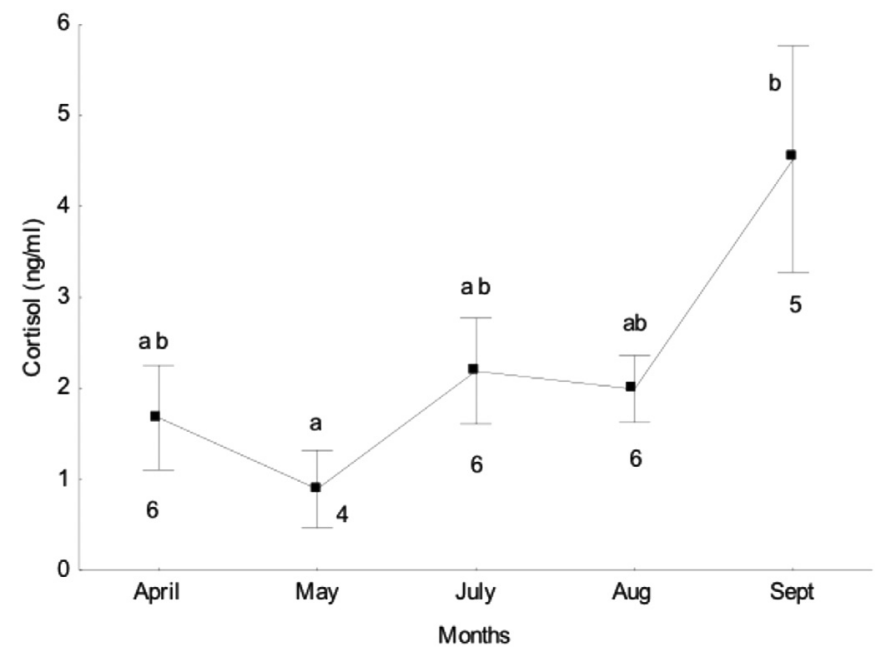

Fig. 5. Plasma cortisol concentrations in each month during the reproductive cycle (number of individuals in each month). Different letters indicate significant differences $(p<0.05)$.

avoid a significant increase of cortisol due the effect of capture, since this increase takes place, depending on the species, between 3 and 4 min onward after applying the stressor (Smith et al., 2015). Haddy and Pankhurst (1999) reported plasma gonadal steroid concentration changes occurring between 15 and $30 \mathrm{~min}$ in black bream Acanthopagrus butcheri, after the stressor had been applied. Despite these differences in previous works, it is clear that when fish are subjected to heavy stressors, they show high levels of plasma cortisol and therefore, the responses generated by these high levels of cortisol could interfere with other steroids and the reproductive process. In addition, the allostatic load (Schreck and Tort, 2016) imposed by the stressor may affect the available energetic resources for reproduction (see Pankhurst, 2016). Nevertheless, in the present work, although fish was subjected to acute stress by hook fishing, we expected that the energetic and reproductive consequences were not affected assuming that fish were not subjected to previous stressors and mainly because the sampling was performed before cortisol levels rose significantly. As confirmed in Figure 5, the levels of cortisol did not rise significantly, except in September, probably due to a general increase of steroids during the reproductive process.

In summary, spawning events in Bay de la Paz were registered for the first time in August in this species, and vitellogenesis was still active in the next month. The onset of vitellogenesis was identified by the presence of early vitellogenic oocytes in May, when water temperatures begin to increase. Maximum T and E2 concentrations in plasma were found in July when all females showed late vitellogenic or mature oocytes. Steroid profiles were those expected for this type of ovarian growth with high levels of E2 in September when vitellogenesis is still active. The information obtained in the present study could be useful for the management of captive broodstock, in order to get sexually mature females and spawnings and promote the success in the culture of this species. In addition, this information may be of great interest for the management of the natural stocks and the preservation of the species in the area where L. peru is more intensively fished and consumed.
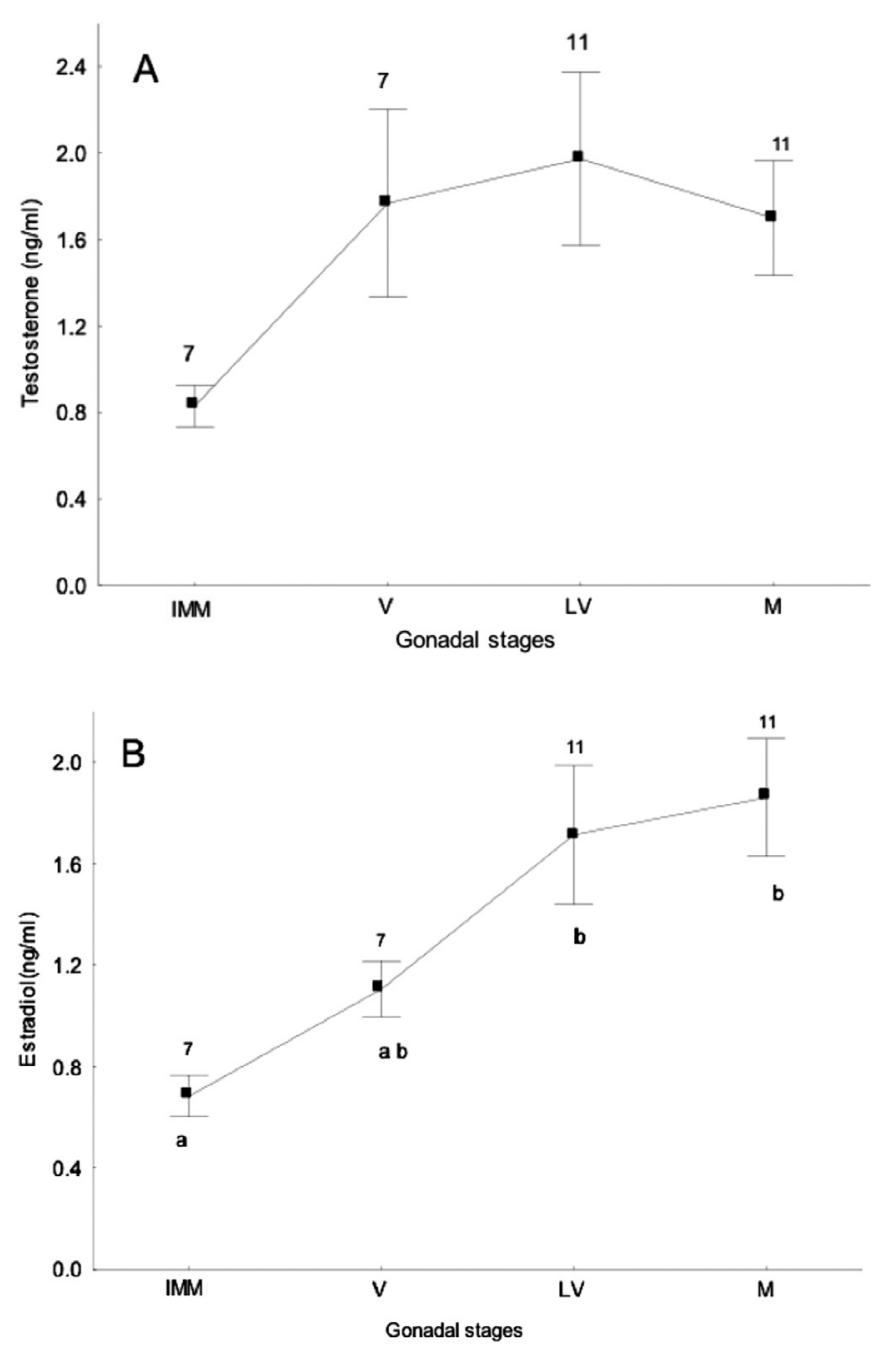

Fig. 6. Plasma steroid concentration observed in each gonadal stages: (a) testosterone, (b) estradiol (number of individuals in each gonadal stage). Abbreviations are indicated in Figure 1. Different letters indicate significant differences $(p<0.05)$.

Acknowledgments. This project was supported by Secretaria de Investigación y Posgrado-Instituto Politécnico Nacional (SIP-IPN grant 20031008) and Consejo Nacional de Ciencia y Tecnología (CONACYT grant 99708). S.D. is a COFAA-IPN and EDI-IPN fellow.

\section{References}

Allen GR, Robertson DR. Fishes of the tropical eastern Pacific. University of Hawaii Press, Honololu, 1994.

Asturiano JF, Sorbera LA, Ramos J, Kime DE, Carrillo M, Zanuy S. 2000. Hormonal regulation of the European sea bass reproductive cycle: an individualized female approach. $J$ Fish Biol 56: 1155-1172.

Barrero M, Small BC, D’Abramo LR, Hanson LA, Kelly AM. 2007. Comparison of estradiol, testosterone, vitellogenin and cathepsin profiles among young adult channel catfish (Ictalurus punctatus) females from four selectively bred strains. Aquaculture 264: 390-397. 
Bromage N, Porter M, Randall C. 2001. The environmental regulation of maturation in farmed finfish with special reference to the role on photoperiod and melatonin. Aquaculture 197: 63-98.

Carragher JF, Pankhusrt NW. 1993. Plasma levels of sex steroids during sexual maturation of snapper, Pagrus auratus (Sparidae), caught from the wild. Aquaculture 109: 375-388.

Clearwater SJ, Pankhurst NW. 1997. The response to capture and confinement stress of plasma cortisol, plasma sex steroids and vitellogenic oocytes in the marine teleost, red gurnard. J Fish Biol 50: 429-441.

Corriero A, Desantis S, Deflorio M, Acone F, Bridges CR, Megalofonou P, De Metrio G. 2003. Histological investigation on the ovarian cycle of the bluefin tuna in the western and central Mediterranean. J Fish Biol 63: 108-119.

Domeier ML, Colin PL. 1997. Tropical reef fish spawning aggregations defined and reviewed. Bull Mar Sci 60: 698-726.

Dumas S, Rosales-Velázquez MO, Contreras-Olguín M, HernándezCeballos D, Silverberg N. 2004. Gonadal maturation in captivity and hormone-induced spawning of the Pacific red snapper Lutjanus peru. Aquaculture 234: 615-623.

Grau A, Crespo S, Riera F, Pou S, Sarasquete MC. 1996. Oogenesis in the amberjack Seriola dumerili Risso, 1810. An histological, histochemical and ultrastructural study of oocyte development. Sci Mar 60: 391-406.

Grutter AS, Pankhurst NW. 2000. The effects of capture, handling, confinement and ectoparasite load on plasma levels of cortisol, glucose and lactate in the coral reef fish Hemigymnus melapterus. J Fish Biol 57: 391-401.

Guraya SS. 1986. The cell and molecular biology of fish oogenesis. Monogr Dev Biol 18: 1-223.

Guzmán JM, Norberg B, Ramos J, Mylonas CC, Mañanós EL. 2008. Vitellogenin, plasma sex steroids and spawning performance of cultured female Senegalese sole (Solea senegalensis). Gen Comp Endocrinol 156: 285-297.

Haddy JA, Pankhurst NW. 1999. Stress-induced changes in concentrations of plasma steroids in black bream, Acanthopagrus butcheri. J Fish Biol 55: 1304-1316.

Hunter JR, Macewicz BJ, Sibert JR. 1986. The spawning frequency of skipjack tuna, Katsuwonus pelamis, from the south Pacific. Fish Bull 84: 895-903.

Hunter JR, Macewicz BJ, Lo CH, Kimbrell CA. 1992. Fecundity, spawning, and maturity of female Dover sole, Microstomus pacificus, with an evaluation of assumptions and precision. Fish Bull 90: 101-128.

Jackson MW, Nieland DL, Cowan JH, Jr. 2006. Dial spawning periodicity of red snapper Lutjanus campechanus in the northern Gulf of Mexico. J Fish Biol 68: 695-706.

Kagawa H, Young G, Nagahama Y. 1983a. Relationship between seasonal plasma estradiol-17 and testosterone levels and in vitro production by ovarian follicles of Amago salmon (Oncorhynchus rhodurus). Biol Reprod 29: 301-309.

Kagawa H, Young G, Nagahama Y. 1983b. Changes in plasma steroid hormone levels during gonadal maturation in female goldfish, Carassius auratus. Bull Japan Soc Sci Fish 49: 1783-1787.

King HR, Pankhurst NW. 2003. Ovarian growth and plasma sex steroid and vitellogenin profiles during vitellogenesis in Tasmanian female Atlantic salmon (Salmo salar). Aquaculture 219: 797-813.

Kobayashi M, Aida K, Hanyu I. 1987. Hormone changes during ovulation and effects of steroid hormones on plasma gonadotropin levels and ovulation in goldfish. Gen Comp Endocrinol 67:24-32.
Kokokiris L, Mourot B, Le Menn F, Kentouri M, Fostier A. 2000. Endocrine changes during the annual reproductive cycle of the red porgy, Pagrus pagrus (Teleostei, Sparidae). Fish Physiol Biochem 23: $1-11$.

Kokokiris L, Le Menn F, Kentouri M, Kagara M. 2001. Seasonal cycle of gonadal development and serum levels of vitellogenin of the red porgy, Pagrus pagrus (Teleostei: Sparidae). Mar Biol 139: 549-555.

Kurita Y, Meier S, Kjesbu OS. 2003. Oocyte growth and fecundity regulation by atresia of Atlantic herring (Clupea harengus) in relation to body condition throughout the maturation cycle. $J$ Sea Res 49: 203-219.

Lam TJ. Environmental influences on gonadal activity in fish, in: WS Hoar, DJ Randall, EM Donaldson (Eds.), Fish Physiology, Vol. IXB, Academic Press, London, 1983, pp. 65-116.

Leslie JK. 1983. Observations of length changes in preserved fresh water young fish. Can Tech Rep Fish Aquat Sci. III-V: 1-19.

Lowerre-Barbieri SK, Ganias K, Saborido-Rey F, Murua H, Hunter JR. 2011. Reproductive timing in marine fishes: variability, temporal scales, and methods. Marine and coastal fisheries: dynamics, management, and ecosystem science. Special section. Fish Reprod Biol 3: 71-91.

Lubzens E, Young G, Bobe J, Cerdà J. 2010. Oogenesis in teleosts: how fish eggs are formed. Gen Comp Endocrinol 165: 367-389.

Lucano-Ramírez G, Villagrán-Santa Cruz M, Ruiz-Ramirez S, LópezMurillo T. 2001. Histology of the oocytes of Lutjanus peru (Nichols and Murphy, 1922) (Pisces: Micale Lutjanidae). Ciencias Marinas 27: 335-349.

Mañanós E, Zanuy S, Le Menn F, Carrillo M, Nuñez J. 1994. Sea bass (Dicentrarchus labrax L.) vitellogenin. I. Induction, purification and partial characterization. Comp Biochem Physiol 107B: 205-216.

Matsuyama M, Adachi S, Nagahama Y, Matsuura S. 1988. Diurnal rhythm of oocyte development and plasma steroid hormone levels in the female red sea bream, Pagrus major, during the spawning season. Aquaculture 73: 357-372.

Milla S, Wang N, Mandiki SNM, Kestemont P. 2009. Corticosteroids: friends or foes of teleost fish reproduction? Comp Biochem Physiol A 153: 242-251.

Mylonas CC, Woods LC, III, Zohar Y. 1997. Cyto-histological examination of post-vitellogenesis and final oocyte maturation in captive-reared striped bass. J Fish Biol 50: 34-49.

Núñez J, Fabrice Duponchelle F. 2009. Towards a universal scale to assess sexual maturation and related life history traits in oviparous teleost fishes. Fish Physiol Biochem 35: 167-180.

Oliveira C, Vera LM, López-Olmeda JF, Guzmán JM, Mañanós E, Ramos J, Sánchez-Vázquez FJ. 2009. Monthly day/night changes and seasonal daily rhythms of sexual steroids in Senegal sole (Solea senegalensis) under natural fluctuating or controlled environmental conditions. Comp Biochem Physiol A 152: $168-175$.

Pankhurst N. The concept of stress in fish, in: CB Schreck, L Tort, AT Farrell, CJ Brauner (Eds.) Biology of Stress in Fish, Fish Physiology Series Vol. 35, Academic Press, Cambridge, MA 2016, pp. 296-333, ISBN: 978-0-12- 802728-8.

Pankhurst NW, Porter MJ. 2003. Cold and dark or warm and light: variations on the theme of environmental control of reproduction. Fish Physiol Biochem 8: 385-389.

Pavlidis M, Greenwood L, Mourot B, Kokkari C, Le Menn F, Divanach P, Scott AP. 2000. Seasonal variations and maturity stages in relation to differences in serum levels of gonadal steroids, vitellogenin, and thyroid hormones in the common dentex (Dentex dentex). Gen Comp Endocrinol 118: 14-25. 
Pickering AD, Pottinger TG, Carragher J, Sumpter JP. 1987. The effects of acute and chronic stress on the levels of reproductive hormones in the plasma of mature male of brown trout, Salmo trutta L. Gen Comp Endocrinol 61: 120-126.

Prat F, Zanuy S, Carillo M, De Mones A, Fostier A. 1990. Seasonal changes in plasma levels of gonadal steroids of sea bass, Dicentrarchus labrax L. Gen Comp Endocrinol 78: 361-373.

Reyna-Trujillo MM. Desarrollo gonádico y época de desove del huachinango Nichols y Murphy 1922 (Pisces: Lutjanidae) en la Bahia de La Paz, B.C.S. Mexico Bachelor thesis, University of Guadalajara, 1993, 69 pp.

Rinchard J, Kestemont P, Kuhn ER, Fostier A. 1993. Seasonal changes in plasma levels of steroid hormones in an asynchronous fish, the gudgeon Gobio gobio L. (Teleostei, Cyprinidae). Gen Comp Endocrinol 92: 168-178.

Rinchard J, Kestemont P, Heine R. 1997. Comparative study of reproductive biology in single- and multiple-spawner cyprinid fish. II. Sex steroid and plasma protein phosphorus concentrations. $J$ Fish Biol 50: 169-180.

Rodriguez L, Begtashi I, Zanuy S, Carillo M. 2000. Development and validation of an enzyme immunoassay for testosterone: effects of photoperiod on testosterone plasma levels and gonadal development in male sea bass (Dicentrarchus labrax L.) at puberty. Fish Physiol Biochem 23: 141-150.

Rotllant J, Ruane NM, Dinis MT, Canario AVM, Power DM. 2006. Intra-adrenal interactions in fish: catecholamine stimulated cortisol release in sea bass (Dicentrarchus labrax L). Comp Biochem Physiol A Mol Integr Physiol 143: 375-381.

Santamaria Miranda A. 1998. Habitos alimenticios y ciclo reproductivo del huachinango, Lutjanus peru, (Nichals y Murphy, 1922) pisces: lutjanidae en Guerrero, Mexico, Master Degree thesis, CICIMAR-IPN, 64 pp.

Schreck CB, Tort L. 2016. The concept of stress in fish. In: CB Schreck, L Tort, AT Farrell, CJ Brauner, eds., Biology of Stress in Fish, Fish Physiology Series, Vol. 35. Academic Press-Elsevier, pp. , ISBN: 978-0-12- 802728-8.

Selman K, Wallace R. 1989. Cellular aspects of oocyte growth in teleosts. Zool Sci 6: 211-231.

Smith MS, Booth NJ, Peterson BC, Stephens WS, Goudie CA, Simco, BA. 2015. Analysis of short-term cortisol stress response in channel catfish by anesthetization with metomidate hydrochloride and tricaine methanesulfonate. J Aquat Anim Health. 27: $152-155$.

Specker JL, Sullivan CV. . Vitellogenesis in fishes: status and perspectives. In: KG Davey, RE Peter, SS Tobe, eds., Perspectives in Comparative Endocrinology. Ottawa: National Research Council of Canada, pp. 304-315.

Sun B, Pankhurst NW. 2004. Patterns of oocyte growth, vitellogenin and gonadal steroid concentrations in greenback flounder. J Fish Biol 64: 1399-1412.

Tyler CR, Sumpter JP. 1996. Oocyte growth and development in the teleost. Rev Fish Biol Fish 6: 287-318.

Cite this article as: Dumas S, Ramirez Luna S, Pintos Terán P, Mañanos E, Tort L. 2018. Seasonal steroid variations in relation to maturity stages in the female Pacific red snapper Lutjanus peru in the Gulf of California, Mexico. Aquat. Living Resour. $31: 34$ 